\title{
Screening Criteria for the Application of Steam Injection and Horizontal Wells
}

\author{
Palmgren C., Renard G. \\ IFP, France
}

\begin{abstract}
Copyright 1985, Steering Committee of the European IOR - Symposium.
This paper was presented at the Eth. European IOR - Symposium in Vienna, Austria, May 15 - 17, 1996

This poper was eelected for presentation by the Stoering Committes, following review of information contained in an abstract

submitted by the author(a). The paper, as presented has not been reviewed by the Steering Commintee.
\end{abstract}

\section{ABSTRACT}

Technical and economic problems of efficient development of heavy oil resources receive large attention in all countries where these resources are abundant. This is particularly the case in Canada and Venezuela where some 70 per cent of the world reserves of heavy oil are located.

World-wide experience to-date indicates that thermal methods, such as steam flood, in-situ combustion and steam-gas injection, are the only effective methods available for the in-situ recovery of the extensive heavy oil resources. In this respect, the emergence of horizontal drilling technology, as well as the slim hole technique, has opened up new perspectives. In the last few years, progress in drilling and completion of horizontal wells have brought this new production tool to a high level of achievement for a wide range of applications.

This paper concentrates on the synergism of thermal methods with less conventional well techniques to improve the recovery in heavy oil deposits. In general, the replacement of conventional vertical wells with horizontal wells and/or multiple slim holes increases the drainage volume against a lower cost. Several promising thermal methods: steam flood, cyclic steam injection, steam-assisted gravity drainage (SAGD) and in-situ combustion in conjunction with horizontal wells and slim hole techniques are reviewed as well as available analytical models to predict oil recovery in the case of homogeneous reservoir properties. For more complicated cases, numerical modelling must still be used.

On the basis of field pilots and numerical modelling, criteria for the appiicability of steamflooding and the SAGD process are defined. It is shown that these two methods can find a wide application in practice and become, in technological and economic respects, effective methods for the recovery of heavy oil deposits.

\section{INTRODUCTION}

Conventional oil reserves amount to some 170 billion $\mathrm{m}^{3}$ of which the main part is located in the Middle-East (59.3 per cent) and the rest is split more or less evenly over the remaining regions of the world. Masters et al. ${ }^{1}$ estimate the identified natural gas reserves at some 130 trillion $\mathrm{m}^{3}$. At the Thirteenth World Petroleum Congress, Tedeschi ${ }^{2}$ presented an estimation of the heavy, extra heavy oil and bitumen resources. The crude oil classification proposed by the World Petroleum Congress is shown in Table 1.

\begin{tabular}{|l|c|c|}
\hline \multicolumn{3}{|c|}{ Table 1. Crude oil classification. } \\
\hline Classification & 'API & $\begin{array}{c}\text { In-situ Viscosity } \\
\text { (Pa.s) }\end{array}$ \\
\hline Light & $>31.1$ & - \\
Medium & $22.3-31.1$ & - \\
Heavy & $10-22.3$ & - \\
Extra heavy & $<10$ & $<10$ \\
Bitumen & $<10$ & $>10$ \\
\hline
\end{tabular}

Heavy, extra heavy and natural bitumen proved plus unproved reserves add up to some 100 billion $\mathrm{m}^{3}$, with the major reserves in Canada (40.8 per cent), Venezuela (27.4 per cent) and the former Soviet-Union (19.4 per cent).

The ever-growing interest in heavy oil resources is explained by their potential in terms of being a possible source of future world energy supply and of having a strategic reserve 


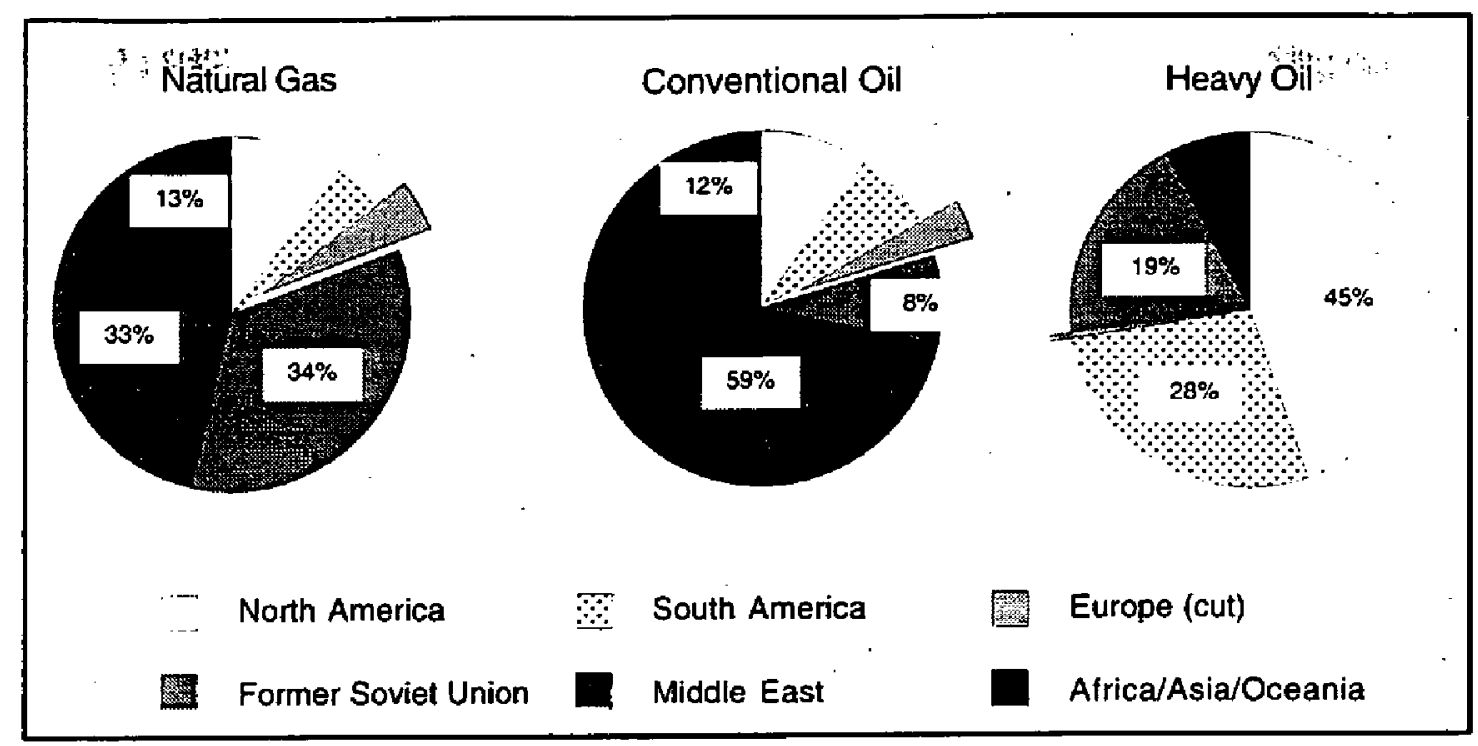

Figure 1. Global geographical distribution of hydrocarbon reserves.

distribution in comparison with the conventional light and medium world oil reserve distribution (Figure 1). By heavy oils we understand, in the remainder of this paper, oils having a specific density below some $20^{\circ} \mathrm{API}$.

Engineering studies have indicated that the main advantages of horizontal over vertical wells are derived from their larger reservoir exposure, which increases productivity, accelerates recovery and reduces coning tendencies ${ }^{3}$.

When the mobility of hydrocarbons is too low, primary recovery even with horizontal wells can become unfeasible. However, in such cases, horizontal wells still have advantages over conventional wells when using thermal methods.
The consequences of using new access technologies to a reservoir in conjunction with well established recovery mechanisms and mobility enhancements for low mobility hydrocarbons are summarised in Table 2, where we also show the resulting possible drainage architecture and recovery processes.

Screening criteria as well as analytical prediction tools exist for most thermal methods. The steam assisted gravity drainage (SAGD) process combines horizontal wells with effective thermal recovery methods. An easy-to-use tool also exists for the preliminary estimation of the steam-assisted gravity drainage process in reservoirs without bottom aquifer. If a bottom aquifer is present,

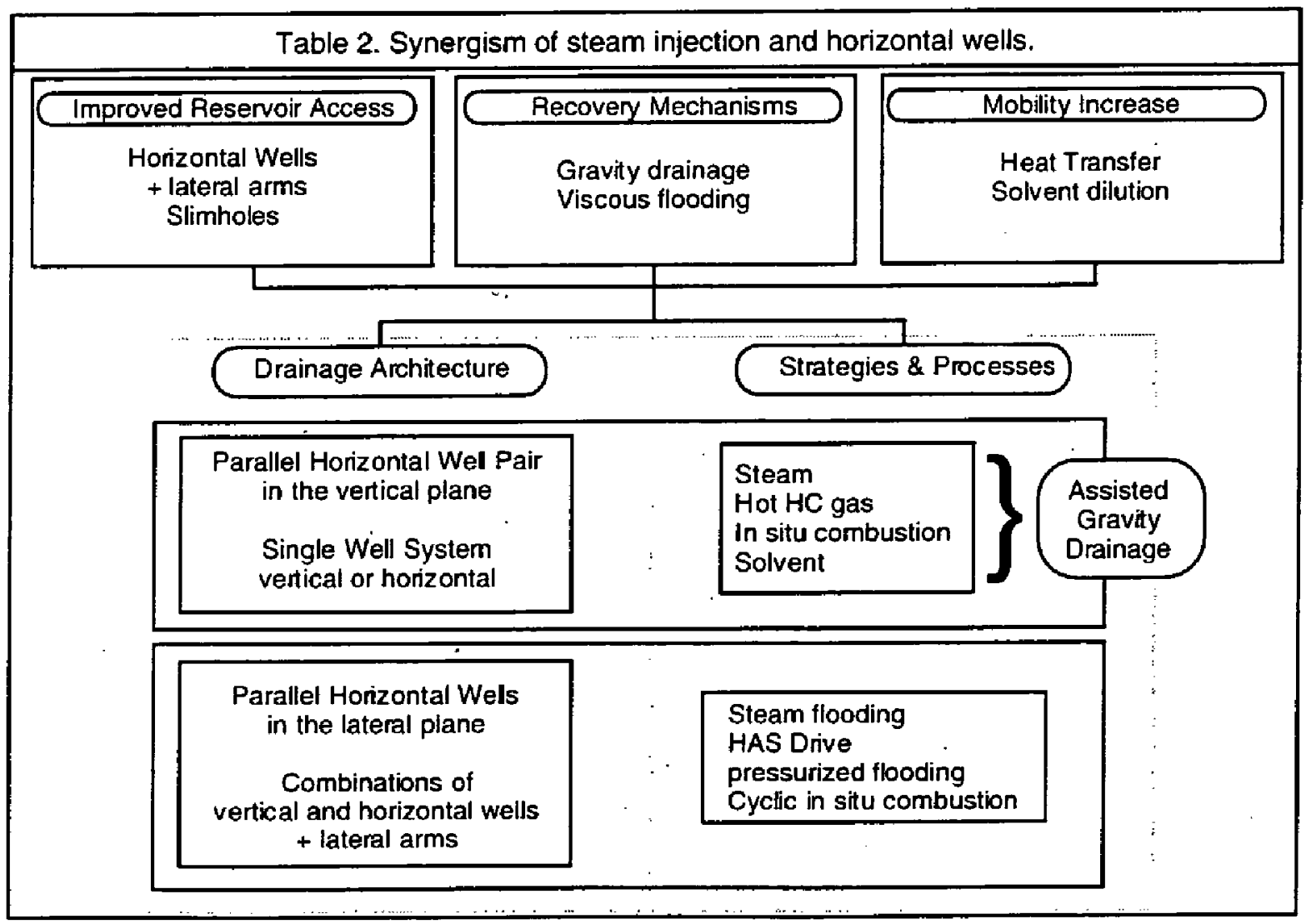


numerical simulations and/or laboratory work are still needed, even for preliminary screening purposes. Besides these current tools, we also present a new comprehensive screening guide, which is a combination of existing criteria and new numerical results obtained-with IFP's SARIP model.

\section{EMERGENCE OF HORIZONTAL WELLS}

In the 70s', theoretical studies initiated by IFP and Elf concluded that horizontal wells could be a viable alternative to produce heavy oil reserves. Following these studies, a challenging application of horizontal drilling technology was the economic recovery of a portion of the 160 million $\mathrm{m}^{3}$ of the $300 \mathrm{mPa} .5$ oil from the Rospo Mare karstic fractured field located in the Adriatic Sea. After this proven success, more and more companies started to drill horizontal wells which allowed economic development of their marginal fields.

The success of horizontal wells remains true, even today in times of an overall lessened economic situation in the petroleum industry. The explosive increase in the number of horizontal wells drilled in Canada in the last few years is remarkable (Figure 2). Eighteen per cent of the drilling licenses issued in 1993 in Canada proposed to drill directional or horizontal wells.

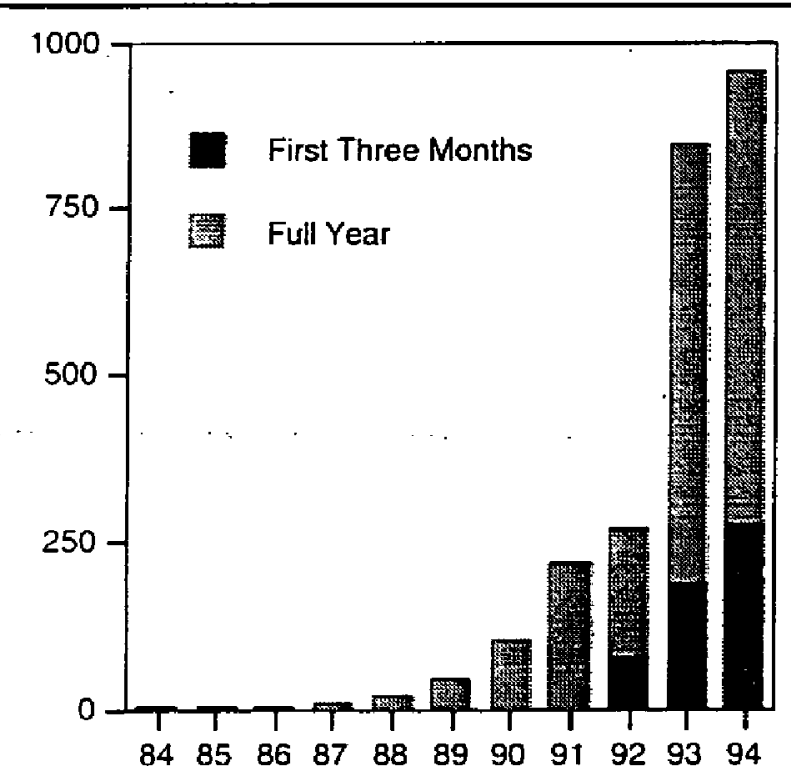

Figure 2. Number of horizontal wells in Canada.

Of course, the exponential increase will eventually flatten out due to the limits of effective applicability and technological know-how. However, recent reports are positive: in the first quarter of 1994 , 273 horizontal wells were drilled, against 188 in the first three months of 1993 and 74 in 1992.

The improvements in drilling technology allow at present to drill single lateral lengths in the kilometres with the toe positioned within the metre. Elf ${ }^{4}$ reported that its horizontal wells develop 2.5 times more of the reservoir at a cost which lies only 50 per cent higher than nearby conventional wells.
Actual costs for horizontal wells steadily decline and at present are approximately CDN\$340 per metre drilled ${ }^{5}$. Another technique has become available thanks to the lateral tie-back tool ${ }^{6}$ developed by Sperry-Sun and CS Resources: the drilling and completion of lateral drain holes more or less perpendicularly from an existing one. The interdisciplinary approach in defining drilling targets has also increased horizontal well applications in more conventional situations and in fields operated in the EOR stage.

\section{SYNERGISM WITH THERMAL METHODS}

Experience to-date indicates that thermal methods are the only effective methods available for the insitu recovery of the extensive heavy oil resources. The current thermal techniques can be divided in four groups:

- hot-water injection.

- steam injection,

- in-situ combustion,

- electromagnetic heating.

For the recovery of heavy oil the injection of hotwater is generally not feasible due to the fact that the amount of heat injected is too small in order to combat the detrimental effect of the viscous forces on vertical and areal sweep efficiency of the hotwater zone.

The combination of in-situ combustion and horizontal production wells for the recovery of heavy oils has been studied in partially scaled laboratory models. Numerical simulations indicate that in-situ combustion with horizontal production wells could be economically feasible for the exploitation of heavy oil fields. At the Brintnell site ${ }^{7}$ in Canada, a project has been started where air is injected through a horizontal well and liquids are produced through two horizontal wells. Other in situ combustion field test involving horizontal wells have been reported; the Eyehill field ${ }^{\beta}$ (Canada), the Battrum field ${ }^{9}$ (Canada), and the Chetopa field ${ }^{10}$ (Kansas, USA).

The application of electro-magnetic heating is currently under study. It has been applied in the field as a well treatment to reduce the skin, but it is too early to decide whether or not it could be applied on an industrial scale.

\section{FIELD APPLICATIONS STEAM INJECTION}

A horizontal well steam injector in a thick, fow permeability naturally fractured reservoir (the Lacq Superieur field) increased production almost six fold, but then steam broke through prematurely in the vertical producers, channelling through the fractures intersected by the well" 1 .

One of the earlier steamed horizontal wells (Cold Lake, Canada) had a length of 245 metres and was operated in three phases: first ten months 
single well continuous injection-production, then two and a half years production from the horizontal well with steam injection from a vertical well positioned directly above, and then at least eight years continued operation with a bottom hole pump installed in the horizontal producer. During the last five years the main recovery mechanism is thought to have been gravity drainage ${ }^{12}$.

Jespersen and Fontaine ${ }^{13}$ discuss the performance of a horizontal well steam injection pilot (North Tangleflags, Canada), which was later expanded to include two horizontal producers and five vertical steam injectors. Steam was injected above the producers. According to the authors, the economic situation in 1991 did not allow field scale expansion. In the Cactus Lake (Canada), a vertical steam injection well was drilled between two horizontal wells. Steam injection commenced June, 1992. No results have been published, yet.

With the objective to improve steam injection and ultimate oil recovery, four ultra short radials (each some 30 metres in length) were drilled and completed from a vertical borehole in the Bremer Fee lease of the Midway-Sunset field (Potter formation $)^{14}$. The vertical well was subjected to a cyclic steam operation and performed well, increasing oil production in comparison with wells not carrying radials. The radial well was later incorporated in a larger pilot comprising one horizontal medium radius well (120 metres) and two vertical wells used as steam injectors. Seventeen vertical producers completed the field pilot. At the time of publication, i.e., some two years after startup, the increase in oil production was not unlike the production response observed in the successful vertical well pattern steam flood in another part of the field.

Three short radials (length some 200 metres) were drilled at the base of the pay zone in a thin homogeneous sand in the Midway-Sunset field. The radials had negligible primary production, but calculations indicate that once the wells have been steam soaked, the horizontals produce 3 to 6 times more than a representative vertical well, against thrice the cost ${ }^{15}$. The pitot was later extended by four medium horizontal wells, and these also performed within expectations. Then three more medium radius wells were drilled and completed. Completion of horizontal wells followed the maxim of "one level of sand retention less than required in vertical wells"16.

Lagoven (Venezuela) studies a combination of vertical and horizontal wells plus steam injection techniques to recover heavy oil in the Cerro Negro area of the Orinoco belt. ${ }^{17}$

The HAS Drive process consists of a vertical steam injector and a vertical producer, connected at the bottom of the pay zone by a horizontal well drilled from one of the underground tunnels present at the Underground Test Facility (UTF) near Fort McMurray in Canada ${ }^{18}$. The other field applications of the SAGD process are also found in
Canada: the UTF horizontal well pilot ${ }^{19}$, in the Peace River ${ }^{20}$ oil sands deposit and at Wolf Lake ${ }^{21}$. The main characteristics of the three SAGD projects are listed in Table 3. The horizontal well designs in Shell's Peace River pilot have been described in detail by Lepper ${ }^{22}$.

\begin{tabular}{|lr|c|c|c|}
\hline \multicolumn{5}{|c|}{$\begin{array}{c}\text { Table 3. Main characteristics of } \\
\text { SAGD field examples. }\end{array}$} \\
\hline \multicolumn{2}{|c|}{ Field } & UTF & $\begin{array}{c}\text { Wolf } \\
\text { Lake }\end{array}$ & $\begin{array}{c}\text { Peace } \\
\text { River }\end{array}$ \\
\hline Depth & $\mathrm{m}$ & 150 & 450 & 550 \\
Net pay & $\mathrm{m}$ & 16 & 35 & 25 \\
Permeability & $\mu \mathrm{m}^{2}$ & 3 & 2 & 0.5 \\
Porosity & $\%$ & 35 & 33 & 28 \\
Soi & $\%$ & 80 & 60 & 80 \\
Pressure & $\mathrm{MPa}$ & 0.45 & 2.8 & 3.6 \\
Viscosity oil & $\mathrm{Pa.s}$ & 1570 & 100 & 200 \\
Well Length & $\mathrm{m}$ & 500 & 800 & 1000 \\
Distance & $\mathrm{m}$ & 5 & 9 & 10 \\
injector/producer & & & & \\
Distance between \\
well pairs
\end{tabular}

\section{FUTURE TECHNOLOGIES}

A major draw back of the SAGD process is the necessity to heat the formation to a temperature well above initial reservoir temperature to ensure sufficient oil mobility. This operating mode suffers from heat losses to surrounding formations. In order to circumvent the problem of heat losses, Butler and $\mathrm{CO}$-workers ${ }^{23}$ have proposed the VAPEX process. Here, a hydrocarbon vapour is injected into the oil bearing formation instead of steam. A judicious choice of the hydrocarbon to use (VAPEX, e.g., initially considered the injection of propane), ensures an optimal process in terms of operating conditions. Oil mobility is no longer assured by heat transfer, but is due to viscosity reduction by solvent dilution into the oil. Oil viscosity reduction by the dilution mechanism is much slower than by heat diffusion as the mass diffusion coefficient is orders of magnitude smalter than the thermal diffusivity.

The injection, as a vapour, of a heavier hydrocarbon with a boiling point well above reservoir temperature combines the heat effect abtained with steam injection with the dilution effect obtained with lighter hydrocarbons ${ }^{24}$

Other processes comprise the co-injection or alternating injection of steam with another gas, that might be non-condensable, or the single-well soak process (Table 2 ).

In the following, focus is placed on the comparative merits of SAGD and steam flooding with horizontal wells for the recovery of heavy oils. Reservoirs with and without bottom aquifer are studied separately due to the influence of the bottom aquitar on the production mechanisms. 


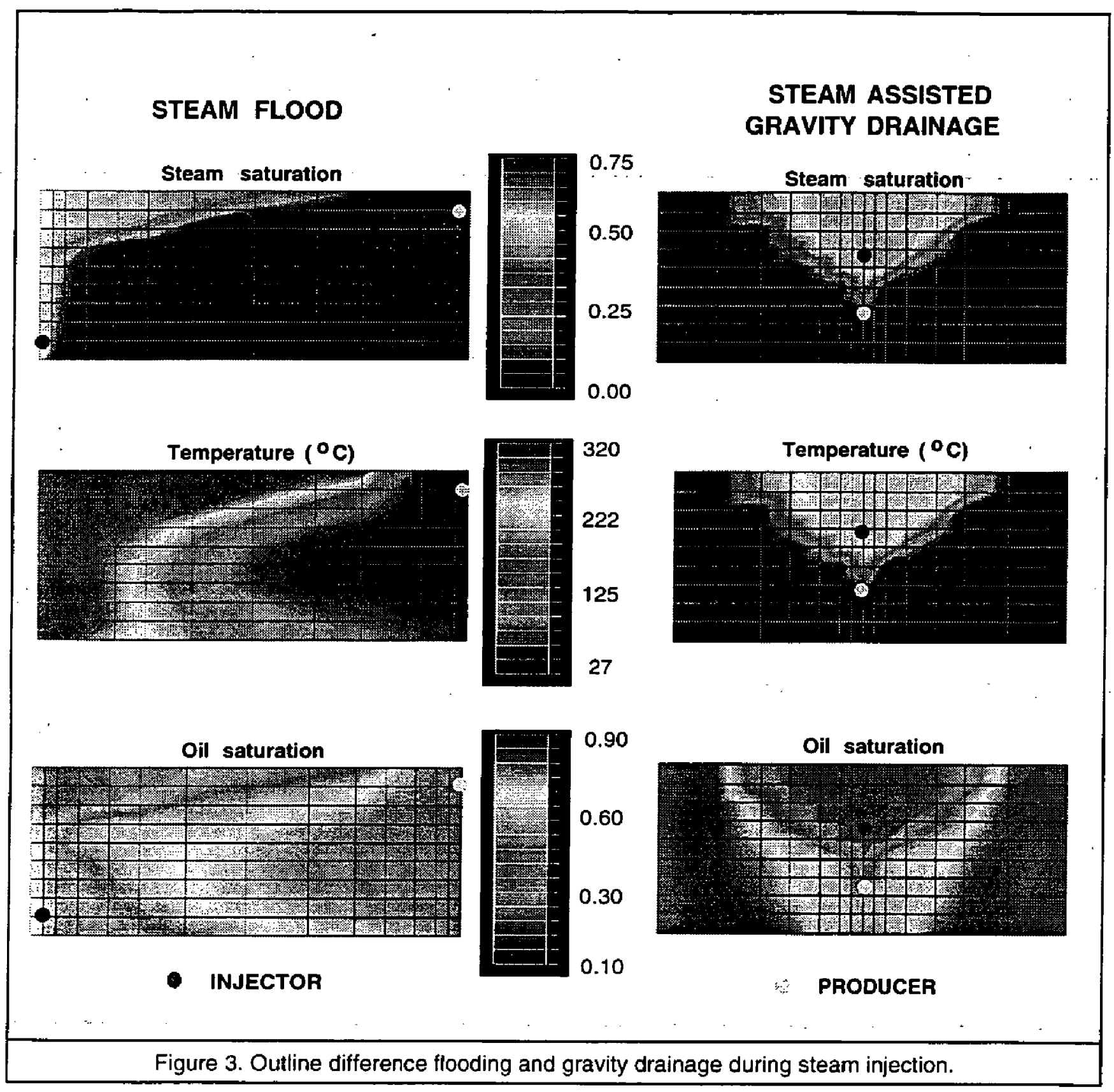

\section{COMPARATIVE STUDY OF SAGD AND STEAM FLOODING IN HEAVY OIL RESERVOIRS IN THE ABSENCE OF BOTTOM AQUIFER}

The use of steam to recover oil can be divided in two modes: the steam soak technique and the steam drive technique. Steam soaking entails the periodic injection of steam into a well, which is closed down for a couple of days after injection of the heat-carrier, and then put back on stream. A large part of the extra oil recovered in this fashion is produced during the first three/four cycles. During steam drive recovery, steam is contínuously injected into the reservoir, where it heats the oil and pushes it towards one or more production wells. The principle is shown on the lett hand side in Figure 3, where we show the temperature field and the gas (steam) and oil saturation distributions during a steam drive between horizontal wells.
Table 4. Selection criteria for conventional well steam flooding.

\begin{tabular}{|l|r|c|}
\hline Criterion & Unit & Value \\
\hline Depth & $\mathrm{m}$ & $<900$ \\
Net pay & $\mathrm{m}$ & $>6$ \\
Porosity & $\%$ & $>20$ \\
$\phi \star S_{o i}$ & $\%$ & $>25$ \\
Permeability & $\mu \mathrm{m}^{2}$ & $>0.25$ \\
Oil density & $\mathrm{kg} / \mathrm{m}^{3}$ & $855-1000$ \\
Oil viscosity & $\mathrm{Pa} . \mathrm{s}$ & $<15$ \\
Transmissibility & $\mu \mathrm{m}^{2} . \mathrm{m} /($ Pa.s) & $>16.4$ \\
Pressure & $\mathrm{MPa}$ & $<10$ \\
\hline
\end{tabular}

Both methods have been extensively used since the early sixties and hence the conditions under which previous experience indicates an effective use of these techniques with vertical wells are wellknown. For preliminary design purposes, this knowledge is summarised in so-called screening criteria, outlining the limits of applicability. We 
intits

istress the fact that screening criteria are affected every time a field is developed and the results of pilots are evaluated. The more or less unchanging criteria for steam flooding sandstone reservoirs are presented in Table 4.

Besides these criteria for vertical wells, simple analytical models have been developed to estimate steam flood project performance in terms of oil recovered and steam injected. These conventional models comprise the frontal advance models, which are based on the heat transfer concept proposed by Marx and Langenheim ${ }^{25}$ and the extreme gravity overlay models ensuing from the discussion presented by Voge|26.

The thermal efficiency of the process has been defined as the fraction of the injected heat remaining inside the reservoir. This definition neglects the fact that heat losses to the cap rock determines the advance rate of the tip of the steam condensation front, and hence the beneficial effects of steam condensation at the tip on the sweep efficiency of the steam drive process ${ }^{27}$. Nonetheless, the thermal efficiency in the Marx and Langenheim model can be calculated as:

$$
E_{\mathrm{hs}}=\frac{1}{t_{D}}\left[\mathrm{e}^{t_{D}} \operatorname{erfc}\left(\sqrt{t_{D}}\right)+2 \sqrt{\frac{t_{D}}{\pi}} \cdot 1\right]
$$

The non-dimensional time is given by

$$
t_{D}=\frac{4 \alpha t}{h^{2}}
$$

The amount of produced oil is directly related to the amount of injected heat, expressed in cold water equivalents, by the Cumulative Oil-Steam Ratio (COSR):

$$
\cos A=\frac{\phi \Delta S \rho_{w}\left(c_{w}+f_{s} L_{v}\right)}{M_{R} \Delta T} E_{h s}
$$

Under conditions of strong gravity override, Vogel proposed to neglect the time it takes for the tip of the steam condensation front to move to the production well, and to approximate steam zone advance by a downward movement of a horizontal steam condensation front. In this case the thermal efficiency of the process is given by:

$$
E_{h s}=\frac{1}{1+2 \sqrt{1+\frac{t_{D}}{\pi}}}
$$

More elaborate models have also been proposed, but these also need more elaborate solution methods, and hence do not lend themselves as easily for desk calculations. These heat balance models can be used straightforwardly for horizontal well process developments (Figure 3).
In the early eighties, Butler ${ }^{28}$ and cotworkerts started to publish on the subject of a recovery method using a horizontal steam injector above a horizontal oil producer. The two wells should not be too far apart in order to establish communication between them as soon as possible. Once there is communication, the wells should be controlled for process optimisation. Oil flows towards the producer by its own weight, once mobilised by the condensing steam. The steam acts as a heat carrier and fills that part of the reservoir from which the oil has drained. The recovery mechanism is shown on the right-hand side in Figure 3 , where we show the temperature field and the gas (steam) and oil saturation distributions during an on-going process.

Screening criteria for the SAGD process have not been published previously. However, Butler and co-workers have pentormed a lot of laboratory studies and some numerical studies in order to delineate the conditions under which the SAGD process could be efficient. They have also initiated the work on models describing the process adequately for a first impression of its efficiency.

The models have been developed over a period of time and each modification is intended to better approximate laboratory results. Reis ${ }^{29}$ presented a similar model but introduced a fitting parameter in the derivation. His equation for the production rate reads:

$$
Q_{0}=2 L \sqrt{\frac{k_{0} g \alpha \phi \Delta S h}{2 a m v_{S}}}
$$

and we have modified his expression for the COSA to be identical to the expression presented above, with the thermal efficiency determined as:

$$
E_{\mathrm{hs}}=\frac{1}{1+\frac{t_{D}}{2 a}+\frac{4}{3} \sqrt{\frac{t_{D}}{\pi}}}
$$

\section{COMPARATIVE STUDY OF SAGD AND STEAM FLOODING IN HEAVY OIL RESERVOIRS IN THE PRESENCE OF AQUIFER}

In the presence of an aquifer, or large water zones located within the pattern area, steam generally flows through the water area towards the producer. Hence, most of the oil is bypassed. This effect is aggravated with increasing oil viscosity at initial temperatures.

No simple-to-use recovery prediction model exists for steam flooding or steam-assisted gravity drainage in the presence of active bottom aquifers. Even the commonly used screening criteria for vertical wells have been determined for reservoirs without an aquifer or where the aquifer did not noticeably influence the recovery mechanism. At present, numerical simulation studies or laboratory studies in partially scaled models serve to delineate the possible application of different recovery. processes and pattern configurations in reservoirs with bottom aquifer. 
Continuous and active aquifers at the bottom of heavy oil reservoirs limit the applicability of conventional steam recovery techniques because steam tends to flow into the water layer, which can lead to excessive heat losses and because conventional production wells may suffer-from extremely high water cuts.

A two-dimensional numerical simulation study was performed using IFP's SARIP compositional and thermal simulator. The numerical study was conducted to investigate the feasibility of the SAGD process with a horizontal well pair to recover oil from heavy oil reservoirs with bottom aquifer. Numerical results show that during steam injection, a fraction of the mobilised oil is displaced into the aquifer. However, most of the trapped oil can be swept to the production well by the flow of water from the aquifer, which is induced by lowering production well pressure at the end of the drainage period.

One of the main concerns for a proper implementation of the SAGD process is an adequate regulation of the horizontal well pair. The prerequisite steam trap control at the production well can be described as the method which keeps the steam chamber close to the producer, without producing any steam. In fact, the production rate needs to balance the drainage rate in an optimised situation. The temperature in the production well is the best indicator of the presence of steam near the wellbore. The measured temperature should be below steam chamber temperature, which is near injector temperature in the vicinity of the well pair. If well temperature is too high compared with steam chamber temperature, then production rate should be decreased. If it is too low, then production rate needs to be increased. This demands continuous changes in production and injection well rate constraints. The field implementation of such a well control system has been described by Edmunds et al. ${ }^{19}$. A similar technique has been implemented in the thermal simulator used for this study. Other approaches have also been proposed.

In one study simulating a laboratory experiment, the production well pressure constraint was set slightly above the measured pressure to prevent steam production 30 .

Another study implemented a "production enthalpy controi" in the SAGD process by coupling the well pressure constraints to a maximum steam rate constraint in the production wel/ ${ }^{31}$.

On the basis of numerical results, criteria for the applicability of steam flooding and the SAGD process are defined. The screening guide shown in Figure 4 is based on possible realistic values for oil net pay thickness, bottom aquifer thickness, insitu oil viscosity and sand quality. The selection criteria are subject to the constraints of not 100 deep reservoirs, i.e., depth of the reservoir is less than $\mathbf{8 0 0}$ metres, the absence of sand production problems, no free gas in the reservoir, and the fact that the heterogeneities present do not influence the recovery mechanism.

\section{CONCLUSION}

Based on the numerical study performed on the steam-assisted gravity drainage process we conclude that,

- it is less affected by 3D effects than steam flooding. Preferential flow paths between

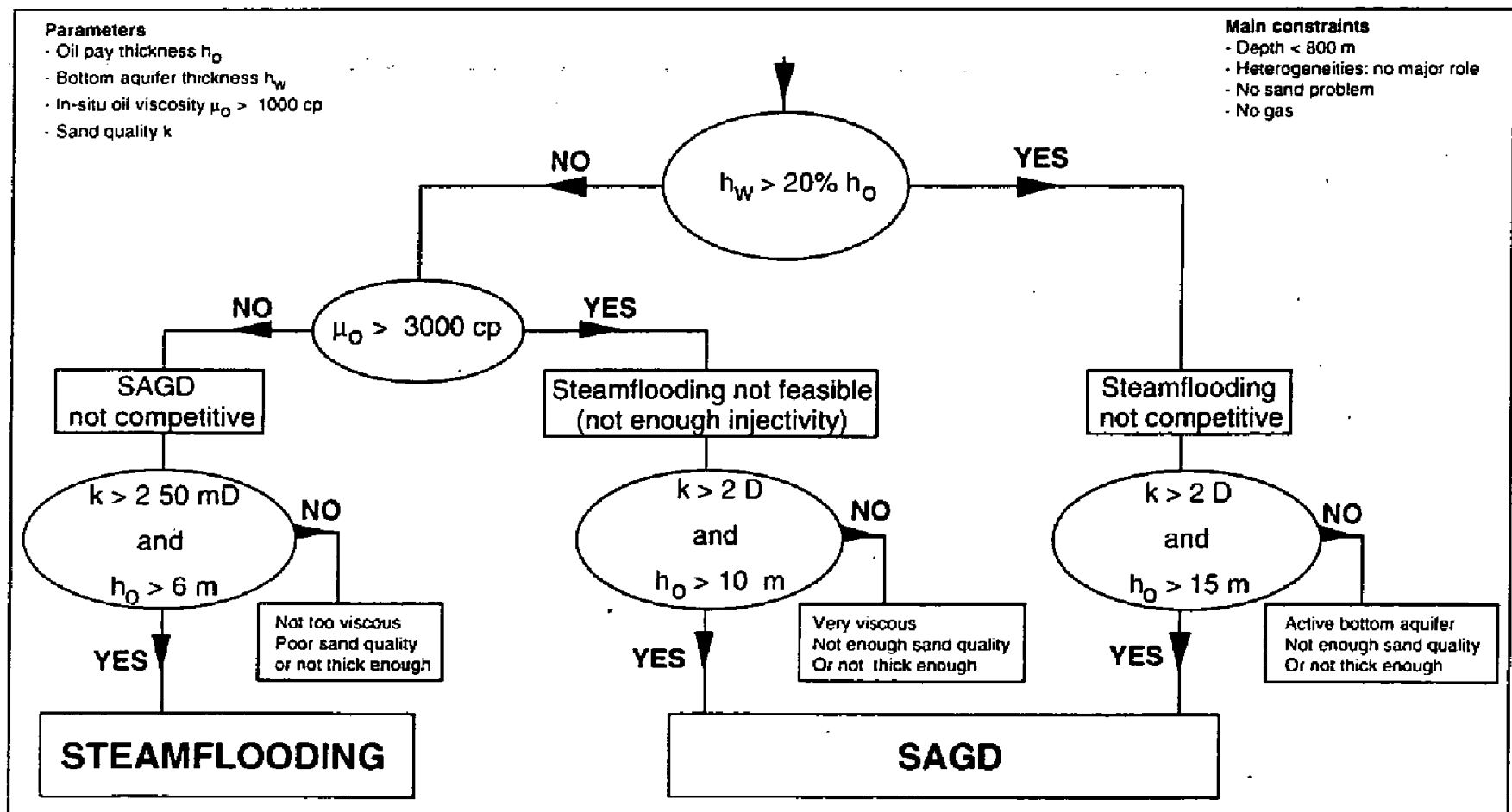

Figure 4. Screening criteria for steam injection methods and horizontal wells. 
horizontal injector and horizontal producer in a line drive configuration can significantly reduce the volumetric sweep efficiency of the injected steam $^{32}$

- it is generally more attractive for reservoirs with bottom aquifer, because recovery is better with less steam consumption (COSR $>0.22$ ). Moreover, if the pressure at which steam is injected is judiciously chosen, the production well is less affected by water coning, and less oil is trapped in the aquifer zone,

- a permeability less than 2 Darcies prevents a good spreading of the steam chamber and limits the benefits of the process,

- process optimisation for implementation requires the use of numerical models. A preliminary estimation of process feasibility may be performed using the screening guide presented in Figure 4,

- optimisation requires regulation of the injector/producer well pair to prevent steam production.

In general, the huge reserves of heavy oils spread over the world present a technical and economic challenge. In our view, production of these reserves could be achieved by thermal methods together with horizontal wells. In this respect, the steam-assisted gravity drainage process involving injection of steam and oil drainage to a horizontal producer is the most promising due to its wide range of applicability, see Figure 4 . The screening criteria give a first estimate for the conditions under which the method might find an application in practice and become, in technological and economic respects, an effective method for the recovery of heavy oil deposits.

\section{ACKNOWLEDGEMENT}

The authors want to thank the Institut Français du Pétrole for permission to publish this paper.

\section{SYMBOLS}

a $\quad$ Empirical constant $(=0.4)$

$c_{w} \quad$ Water specific heat capacity

COSR Cumulative Oil Steam Ratio

$E_{\text {hs }} \quad$ Thermal efficiency

$f_{s} \quad$ Steam quality

$g \quad$ Gravitational acceleration

$h \quad$ Effective process thickness

$h_{0}$

$h_{w}$

$k$

Oil column thickness

Bottom aquifer thickness

Absolute permeability

$L \quad$ Horizontal well length

$L v \quad$ Heat of vaporisation

$M_{R} \quad$ Effective matrix heat capacity

$m \quad$ Oil viscosity parameter $(=3)$

$Q_{0} \quad$ Oil production rate
$T_{s} \quad$ Steam chamber temperature

$t \quad$ Time

$t_{D} \quad$ Non-dimensional time

$S_{o i} \quad$ Initial oil saturation

$\alpha \quad$ Effective thermal diffusivity

$\Delta S \quad$ Movable oil saturation

$\Delta T \quad$ Temperature difference

$\phi \quad$ Porosity

$\mu_{0} \quad$ Dynamic oil viscosity

$v_{s} \quad$ Kinematic oil viscosity at $T_{s}$

$\rho_{w} \quad$ Water density

SAGD Steam-Assisted Gravity Drainage VAPEX In situ VAPour EXtraction methods

\section{REFERENCES}

1 C.D. Masters, D.H. Root, and E.D. Attanasi: "World resources of crude oil and natural gas", Proc. Thirteenth World Petroleum Congress, 51-67, Buenos Aires, October 20-25, 1991.

$2 M$. Tedeschi: "Reserves and production of heavy crude oil and natural bitumen", Proc. Thirteenth World Petroleum Congress, 51-67, Buenos Aires, October 20-25, 1991.

3 G. Renard and J-C. Sabathier: "Integration of horizontal drilling into reservoir management practice", 7th IOR Symposium, Moscow, October 27-29, 1993.

4 Ph. Coffin: "Horizontal well evaluation after 12 years", paper SPE 26618 presented at the 66th Annual Techn. Conf. and Exhibition, Houston, October, 3-6, 1993.

5 G. Renard, R. Greenslade, J.P Fossey, E. Vandenbroucke and J.M. Dupuy: "Horizontal wells for the primary production of heavy oil reservoirs. Theoretical basis and field examples", paper presented at the Conference on Problems of complex exploration and production of hard-to-recover oils and natural bitumens, Kazan, October 4-7, 1994.

6 R.C. Smith, L. A. Hayes and J. F. Wilkin: "The Lateral Tie-Back System: The ability to drill and case multiple laterals", IADC/SPE 27436, 1994 IADC/SPE Conference, Dallas, February, 15-18.

7 "AOSTRA backs two new heavy oil projects", Improved Recovery Week, March 21, 1994.

8 R.J. Morgan: "Can horizontal wells inject new life into an old combustion pilot", paper $\mathrm{N}^{\circ} 25$ presented at the 5th Petroleum Conterence of the Petroleum Society of CIM and CANMET, Regina, October 18-20, 1993.

9 B.G. Ames, R.E. Grams and P.N. Pebdani: "Application of horizontal well technology in a mature EOR project: Battrum Field, Saskatchewan, Canada", paper ISC 11 presented at the Symposium Field Application of In Situ Combustion - Past Pertormance / Future Application, Tulsa, April 21-22, 1994.

10 R.M. Satchwell, L.A. Johnson Jr. and R. Trent: "Shallow oil production using horizontal wells 
with enhanced oil recovery techniques", paper ISC 12 presented at the Symposium Field Application of In Situ Combustion - Past Performance / Future Application, Tulsa, April $21=22,1994$

11 B.C. Sahuquet, A.M. Spreux, B. Corre and M.P. Guittard: "Steam injection in a lowpermeability reservoir through a horizontal well in Lacq Superieur Field", paper SPE 20256 presented at the 65th Annual Technical Conference and Exhibition of the SPE, New Orleans, September 23-26, 1990.

12 K.O. Adegbesan, R.P. Leauté and D.E. Courtnage: "Performance of a thermal horizontal well pilot", paper SPE 22892 presented at the 66th Annual Technical Conference and Exhibition, Dallas, October 69, 1991.

13 P.J. Jespersen and T.J.C. Fontaine: "The Tangleflags North pilot: A horizontal well steam flood", J.Can.Petr.Techn., Vol. 32, Nr. 5, 5257, May 1993.

14 S.M. Buller: "Evaluation of horizontal, radial, and vertical injection wells in a pilot steam flood", paper SPE 24630 presented at the 67 th Annual Technical Conference and Exhibition, Dallas, October 4-7, 1992.

15 D.E. Carpenter and S.C. Dazet: "Horizontal wells in a steamdrive in the Midway-Sunset Field", paper SPE 24127 presented at the SPE/DOE Eighth Symposium on EOR, Tulsa, April 22-24, 1992.

16 A.B. Speirs and P.B. Warren: "Horizontal well experience in California thermal reservoirs", paper $N^{\circ}$ 94-56 presented at the Canadian SPE/CIM/CANMET International Conference on Recent Advances in Horizontal Well Applications, March 20-23, 1994.

17 R.L. Trebolle, J.P. Chalot and R. Colmenare: "The Orinoco heavy oil belt pilot projects and development strategy", paper SPE 25798 presented at the Thermal Operations Symposium, Bakersfield, February 8-10, 1993.

18 J.H. Duerksen, D.J. Anderson, D.J McCallum and J.C. Suggett: "HASDrive pilot performance at the AOSTRA underground test facility", Proc. AOSTRA Our Petroleum Future Conference, Alberta, April 4-7, 1993.

19 N.R. Edmunds, J.A. Haston and D.A. Best: "Analysis and implementation of steam assisted gravity drainage at the AOSTRA UTF", paper $N^{\circ} 125$ presented at the 4th UNITAR/UNDP International Conference on Heavy Crude \& Tar Sands, Edmonton, August 7-12, 1988.

20 R.A. Hamm and T.S. Ong: "Enhanced steam assisted gravity drainage - a new horizontal well recovery process for Peace River, Canada", paper $\mathrm{N}^{\circ}$ 94-52 presented at the Canadian SPE/CIM/CANMET International Conference on Recent Advances in Horizontal Well Applications, March 20-23, 1994.
21 A.F. Kuckes, J. McMahon, A.G. Nord, D.A. Schilling and J. Morden: "New electromagnetic surveying/ranging method for drilling parallel horizontal twin wells", paper IADC/SPE 27466 presented - at the - IADC/SPE -Drilling Conference, Dallas, February 15*18, 1994.

22 B. Lepper: "Production casing performance in a thermal field", paper No. 94-07 presented at the 48th Annual Technical Meeting of the Petroleum Society of CIM and AOSTRA, Calgary, June 12-15, 1994.

23 R.M. Butler: Horizontal Wells for the Recovery of Oil, Gas and Bitumen, CIM Petroleum Society Monograph Number 2, Calgary, 1994.

24 C.T.S. Palmgren and N.R. Edmunds: "High temperature naphtha to replace steam in the SAGD process", paper SPE 30924 to be presented at the International Heavy Oil Symposium, Heavy Oil, Oil Sands, Thermal Operations - Profitability through Technology, Calgary, June 19-21, 1995.

25 J.W. Marx and R.H. Langenheim: "Reservoir heating by hot fluid injection", Trans. AIME, 216, 312-315, 1959.

26 J.V. Vogel: "Simplified calculations for steam floods", J.Petr.Tech., July 1984, 1127-1136.

27 R.R.G.G. Godderij and J. Bruining: "A new model to predict steam override and viscous fingering in heterogeneous reservoirs", paper SPE 29661 presented at the SPE Western Regional Meeting, Bakersfield, March 8-10, 1995.

28 R.M. Butler: Thermal Recovery of Oil \& Bitumen, Prentice Hall, Englewood Cliffs, 1991.

29 J.C. Reis: "A steam assisted gravity drainage model for tar sands: Linear geometry", J.Can.Petr.Tech., Vol. 31, No. 10, 14-20, December 1992.

30 L." Chow and R.M. Butler: "Numerical simulation of the steam-assisted gravity drainage process", paper 94-63 presented at the 45th Annual Technical Meeting of the Petroleum Society of CIM, Calgary, June 1215, 1994.

31 D. Law, T. Nasr and S. Lorimer: "Numerical simulation of steam-assisted gravity drainage using paired horizontal wells", abstract of paper 26 presented at the Sixth UNITAR International Conference on Heavy Crude and Tar Sands, Houston, February 12-17, 1995.

32 Y.L. Le Gallo and M.J. Latil: "Modeling thermal and pressure drops for multiphase flow in thermal horizontal wells", paper SPE 26077 presented at the Western Regional Meeting, Anchorage, May 26-28, 1993. 